\title{
LEVEL OF KNOWLEDGE REGARDING HUMAN IMMUNODEFICIENCY VIRUS/ACQUIRED IMMUNE DEFICIENCY SYNDROME AND PEOPLE LIVING WITH HUMAN IMMUNODEFICIENCY VIRUS AMONG HEALTH-CARE STUDENTS OF SELECTED COLLEGES IN CHENNAI
}

\author{
LATHA MANGESWARI ${ }^{1}$, KANNIAMMAL $\mathrm{C}^{2}$, JAIDEEP MAHENDRA ${ }^{3}$ \\ ${ }^{1}$ Department of Medical Surgical Nursing, Meenakshi College of Nursing, Chennai, Tamil Nadu, India. ${ }^{2}$ Department of Medical Surgical \\ Nursing, SRM College of Nursing, Chennai, Tamil Nadu, India. ${ }^{3}$ Department of Periodontology and Implantology, Meenakshi Ammal Dental \\ College \& Hospital, Chennai, Tamil Nadu, India. Email: kanniammal@yahoo.co.in
}

Received: 03 October 2016, Revised and Accepted: 17 October 2016

ABSTRACT

Objective: The aim of the study was to assess the level of knowledge among health-care students (HCS) toward human immunodeficiency virus/acquired immune deficiency syndrome (HIV/AIDS) and people living with HIV (PLHIV) in dental and nursing colleges at Chennai.

Methods: A quantitative approach and descriptive research design were adopted for the present study. HIV knowledge questionnaire- 45 was used to assess the level of knowledge regarding HIV and PLHIV. Nonprobability convenient sampling technique was used for the selection of samples.

Results: The collected data were analyzed using SPSS. Among 600 HCS, 274 (46\%) had inadequate knowledge, 191 (32\%) had moderately adequate knowledge, and about 135 (23\%) students had adequate knowledge. The mean knowledge score was 10.94 .

Conclusion: HCS are in need of intense teaching program with various teaching methods which help to enhance their knowledge level and to eliminate the fear and stigma about handling of PLHIV.

Keywords: The health-care students, Level of knowledge, Human immunodeficiency virus/Acquired immune deficiency syndrome, People living with human immunodeficiency virus.

(c) 2017 The Authors. Published by Innovare Academic Sciences Pvt Ltd. This is an open access article under the CC BY license (http://creativecommons. org/licenses/by/4. 0/) DOI: http://dx.doi.org/10.22159/ajpcr.2017.v10i2.15503

\section{INTRODUCTION}

Human immunodeficiency virus (HIV) attacks the body's immune system, specifically the CD4 cells (T-cells), which help the immune system fight off infections. If left untreated, HIV reduces the number of CD4 cells (T-cells) in the body, making the person more likely to get infections or infection-related cancers. These opportunistic infections or cancers take advantage of a very weak immune system and signal that the person has acquired immune deficiency syndrome (AIDS), the last state of HIV infection.

No effective cure for HIV currently exists, but with proper treatment and medical care, HIV can be controlled. The medicine used to treat HIV is called antiretroviral therapy or ART. The compliance of ART can dramatically prolong the lives of many people with HIV, keep them healthy, and greatly lower their chance of transmitting the virus to others. In this view, the role of health-care personnel is inevitable. The monitoring of people living with HIV (PLHIV) involves a broad dimension of closely-associated knowledge, skills, and interfaces, and the detailed understanding is crucial for the decision-making process of the best strategies for a successful therapy [1].

Perception of HIV has been topical due to its central place in determining attitudes and care for people living with HIV/AIDS and having implications for the containment of the epidemic. People living with HIV/AIDS face social stigmatization due partly to a misconception in the perception of the disease and people living with it and students are not left out in this stigmatization and discrimination [2].

The world has halted and reversed the spread of HIV. The epidemic has been forced into decline. New HIV infections and AIDS-related deaths have fallen dramatically since the peak of the epidemic. Now, the response is going one step further ending the AIDS epidemic by 2030 [3]. More than 30 years since the disease was first described in 1981, HIV remains a leading cause of ill-health and mortality while investments in the HIV response have achieved unprecedented results globally. 2.0 million new infections and 1.2 million deaths have occurred. 7 out of 10 PLHIV are in sub-Saharan Africa, where HIV is a leading cause of death among adults, women of child-bearing age and children [4].

\section{Need for the study}

The average cost of treating a person with HIV over the course of their lifetime is $\$ 379,668$. The CDC, 2015 [5] reports that preventive interventions are deemed to be cost-effective in the prevention of HIV infection. HIV/AIDS is mainly affecting the young adults in the age group of 15-24 years thus retarding the economic growth of the country. Adolescence aged 10-19 years of age accounting for nearly $23 \%$ of the population of India is exposed to the risk of being victims of HIV/AIDS. Adolescence age is the time when they are interested in sexual relationships. Immature reproductive tracts make them more susceptible to HIV/AIDS. With the influence of media and the breakdown of traditional family structures, and in the absence of organized institutions for imparting sex education, they tend to learn about sexual and reproductive health from unreliable sources resulting in the perpetuation of myths regarding safe sex and reproductive health.

Grover et al. [6] in their study declared that only $28 \%$ students have excellent knowledge regarding HIV/AIDS, and certain misconceptions were prevalent regarding mode of transmission. Hamid Albujeer et al. [7] in their study among Iraqi medical and dental students' knowledge about HIV/AIDS awareness, said that Knowledge of about half of the medical students (54\%) was at an intermediate level and of $27.1 \%$ students was at a good level; more than half of the dental students $(68.2 \%)$ had an intermediate level, and $10.5 \%$ had a good level of knowledge. 
Common misconceptions among the respondents about HIV/AIDS were HIV transmission through hugging, sharing toilet seats, towels, utensils, shaking hands, and even mosquito bites. So as the low level of knowledge among health-care people toward HIV-positive people evident in many existing studies and personal experience with healthcare students (HCS) motivated to assess the level of knowledge of the HCS about HIV/AIDS and PLHIV. The aim of this study was (1) to assess the level of knowledge on HIV/AIDS and PLHIV among HCS, (2) to associate the level of knowledge on HIV/AIDS and PLHIV among HCS with their selected demographic variables.

\section{METHODS}

Quantitative approach and descriptive research design were selected for the study. After collecting the demographic details of the students, the knowledge level of the students was assessed using structured knowledge questionnaire (KQ). The sample of the study $(n=600)$ consisted of $(n=300)$ 1st year undergraduate nursing students and $(n=300)$ BDS 1st year students in Chennai were selected by nonprobability convenient sampling technique.

The tool consists of two parts. Part-1 consisted demographic data of age, sex, level of education, place of education, father's occupation, family income, source of information, formal education in HIV/AIDS, donated blood, and received blood. Part-2 consisted of HIV/AIDS KQ. The HIV-KQ-45 formulated by Carey and Schroder (2002) is a standardized tool. The modified KQ with 30 items are related to general information about HIV/AIDS, general awareness, disease nature, transmission, treatment and prevention, and positive living for PLHIV. Score interpreted as 0-10 - inadequate knowledge, 11-20 moderately adequate knowledge, and 21-30 adequate knowledge. Content validity of the questionnaire was obtained from experts. Reliability of the 30 -item KQ in the study population was tested using test-retest reliability method $(\mathrm{r}=0.7)$.

The ethical approval for the study was obtained from the Institutional Ethical Committee. After giving verbal explanation about this study, written acceptance was obtained from the students who were willing to participate in this study. Their privacy and anonymity also were respected and maintained.

\section{RESULTS}

Of 600 students selected $515(86 \%)$ were in the age group of $17-18$ years, and $20(3 \%)$ were in the age group of $21-22$ years. With regard to gender, the majority were females 404 (67\%). 581 (97\%) completed their higher secondary schooling. Concerning to family monthly income $279(47 \%)$ had an income of Rs $>30,000$. With regard to sources of information about HIV/AIDS, 286 (48\%) received through web, media, and newspaper as shown in Table 1.

Most of the HCS, 593 (99\%) have not received any formal information about HIV/AIDS (seminar, class, and any certificate course), only $7(<2 \%)$ students received information about HIV/AIDS. This was shocking news in this period among the young adult population who studied formal education for past 17 years. Regarding blood donation, only $4(0.6 \%)$ students donated blood for others, and 596 (99\%) had not donated blood. It shows the fear and unawareness toward blood donation. The HCS knowledge level was not associated with sex, family income, father's occupation, the source of information, and blood donation.

Table 2 illustrates that among 600 HCS, 274 (46\%) had inadequate knowledge, 191 (32\%) had moderately adequate Knowledge, and $135(23 \%)$ had adequate knowledge. The mean knowledge score was 10.93.

Table 3 reveals that $52 \%$ of the students perceived that HIV and AIDS were same $0.55 \%$ believed that there is a cure for AIDS $0.60 \%$ were not accepting that a person with HIV can look and feel healthy
Table 1: Frequency and percentage distribution of demographic variables of HCS $(n=600)$

\begin{tabular}{|c|c|c|}
\hline SI. No. & Demographic variable & Frequency (\%) \\
\hline \multirow[t]{4}{*}{1} & Age (in years) & \\
\hline & $17-18$ & $515(86)$ \\
\hline & $19-20$ & $65(11)$ \\
\hline & $21-22$ & $20(3)$ \\
\hline \multirow[t]{3}{*}{2} & Gender & \\
\hline & Male & $196(33)$ \\
\hline & Female & $404(67)$ \\
\hline \multirow[t]{4}{*}{3} & Completed educational status & \\
\hline & HSS & $581(97)$ \\
\hline & Degree & $6(1)$ \\
\hline & Diploma/certificate course & $13(2)$ \\
\hline \multirow[t]{3}{*}{4} & Educated at & \\
\hline & Rural (village) & $320(53)$ \\
\hline & Urban (city/town) & $280(47)$ \\
\hline \multirow[t]{4}{*}{5} & Fathers' occupation & \\
\hline & Daily wages & $153(25)$ \\
\hline & $\begin{array}{l}\text { Professionals (teaching, medical, } \\
\text { paramedical, engineering, etc.) }\end{array}$ & $218(36)$ \\
\hline & Business & $229(38)$ \\
\hline \multirow[t]{4}{*}{6} & Family income/month (in Rs) & \\
\hline & $10,000-20,000$ & $243(40)$ \\
\hline & $20,001-30,000$ & $78(13)$ \\
\hline & $>30,000$ & $279(46)$ \\
\hline \multirow[t]{6}{*}{7} & Sources of information & \\
\hline & Web/media/newspaper & $286(47)$ \\
\hline & Teacher & $17(2)$ \\
\hline & Parents & $14(2)$ \\
\hline & Friends & $230(38)$ \\
\hline & Books/others & $53(8)$ \\
\hline \multirow[t]{4}{*}{8} & Received formal information about & \\
\hline & $\begin{array}{l}\text { HIV/AIDS (seminar, class, and any } \\
\text { certificate course) }\end{array}$ & \\
\hline & Yes & $7(2)$ \\
\hline & No & $593(98)$ \\
\hline \multirow[t]{3}{*}{9} & Received blood from others & \\
\hline & Yes & $5(1)$ \\
\hline & No & $595(99)$ \\
\hline \multirow{3}{*}{10} & Donated blood for others & \\
\hline & Yes & $4(1)$ \\
\hline & No & $596(99)$ \\
\hline
\end{tabular}

HIV: Human immunodeficiency virus, HCS: Health-care students, AIDS: Acquired immune deficiency syndrome, PLHIV: People living with human immunodeficiency virus

Table 2: Overall level of knowledge of the HCS about HIV/AIDS and PLHIV ( $n=600)$

\begin{tabular}{lll}
\hline Level of knowledge & $\mathbf{n}(\%)$ & Mean \pm SD \\
\hline Adequate & $135(23)$ & $10.93 \pm 6.40$ \\
Mod. adequate & $191(32)$ & \\
Inadequate & $274(46)$ & \\
\hline
\end{tabular}

SD: Standard deviation, HIV: Human immunodeficiency virus, HCS: Health-care students, AIDS: Acquired immune deficiency syndrome, PLHIV: People living with human immunodeficiency virus

actually which is possible very well $0.65 \%$ declared that people who have been infected with HIV quickly show serious signs of being infected which are not happening all the time. The table further shows that $55 \%$ showed the fear that a person can get HIV from sharing toilet and by giving blood $0.56 \%$ were aware that HIV is not transmitted by kissing and hugging $0.43 \%$ were believing that the person will get HIV by sharing the clothes and utensils that were used by the PLHIV.

It is clear from the table that $40 \%$ of the students perceived that HIV will not be transmitted by eating the food which is prepared by the 
Table 3: Item wise analysis of knowledge on HIV among HCS

\begin{tabular}{|c|c|c|c|c|}
\hline S. No. & Items & True $\%$ & False \% & Not known \% \\
\hline 1 & HIV and AIDS are the same thing & 52 & 18 & 30 \\
\hline 2 & There is a cure for AIDS & 55 & 19 & 26 \\
\hline 3 & A person with HIV can look and feel healthy & 22 & 60 & 18 \\
\hline 4 & People who have been infected with HIV quickly show serious signs of being infected & 65 & 12 & 23 \\
\hline 5 & Coughing and sneezing DO NOT spread HIV & 43 & 25 & 32 \\
\hline 6 & It is possible to get HIV when a person gets a tattoo & 70 & 10 & 20 \\
\hline 7 & A person can get HIV from sharing of toilet & 55 & 24 & 21 \\
\hline 9 & HIV is not spread by kissing and hugging & 56 & 32 & 12 \\
\hline 10 & One will get HIV by using the clothes and utensils used by the PLHIV & 43 & 13 & 44 \\
\hline 11 & HIV will spread by eating the food which is prepared by the PLHIV & 40 & 30 & 30 \\
\hline 12 & Children can play with HIV-infected children & 48 & 32 & 20 \\
\hline 13 & HIV can be spread by mosquitoes & 45 & 22 & 33 \\
\hline 14 & The use of condoms could decrease the risk of HIV transmission & 42 & 31 & 27 \\
\hline 15 & HIV could be transmitted from mother to baby & 73 & 7 & 20 \\
\hline 16 & All pregnant women infected with HIV will have babies born with AIDS & 70 & 8 & 22 \\
\hline 18 & Eating healthy food can keep a person away from getting HIV & 60 & 24 & 16 \\
\hline 19 & There is a vaccine that can stop adults from getting HIV & 7 & 60 & 33 \\
\hline 20 & AIDS is the cause of HIV & 60 & 25 & 15 \\
\hline
\end{tabular}

HIV: Human immunodeficiency virus, HCS: Health-care students, AIDS: Acquired immune deficiency syndrome, PLHIV: People living with human immunodeficiency virus

PLHIV and 30\% were denying. Most of the HCS (70\%) are panic that all pregnant women infected with HIV will have babies born with AIDS. Regarding knowledge on treatment and prevention 53\% were not accepting that HIV is killed by bleaching powder solution. About $60 \%$ said that eating healthy food can keep a person away from getting HIV. Regarding HIV vaccination, $60 \%$ did not accept the concept that there is a vaccine that can stop adults from getting HIV. $48 \%$ said that children can play with HIV-infected children, whereas $32 \%$ were afraid that the children will get HIV if they are allowed to play with them. $45 \%$ had the misconception that, the transmission of HIV can be through mosquito bites.

\section{DISCUSSION}

Negative attitudes from health-care personnel have generated anxiety and fear among PLHIV and AIDS. Poor knowledge and fear interact in unexpected ways that allow stigma and discrimination to persist. People maintain both correct and incorrect knowledge. Even doctors and nurses denied them to care in hospitals and clinics out of uninformed fears and judgmental attitude. This palpable ignorance, apathy, discrimination, and stigmatization created room for extreme misinformation and skepticism.

The present study findings revealed that among 600 HCS, 274 (46\%) had inadequate knowledge, 191 (32\%) had moderately adequate knowledge, and 135 (23\%) had adequate knowledge.

Goel et al. [8] also highlighted in their study to assess the HCS opinion regarding the mode of spreading effective and correct awareness about HIV/AIDS and the students revealed that they obtained information regarding HIV/AIDS through television, newspaper/magazine, and peers which correlate with the present study findings that television appears to be the main source of information (47\%) on HIV/AIDS.

Christina and Konstantinos [9] conducted a study to assess the knowledge, attitudes, and behaviors of student nurses on HIV/AIDS AND declared that the majority of participants (95\%) believed that the use of condoms could decrease the risk of HIV transmission which supports the current study results of condom usage in prevention of HIV (42\%), and $66 \%$ of HIV could be transmitted from mother to baby which is matching the result with the current study (73\%).
HIV infection is not only a significant health problem but also one of the most important social issues of the $21^{\text {st }}$ century. Health-care students should be prepared to face the challenges in future. Their training should not only include the role required to play but also there should be continuous training programs to sustain the effect. So, it could enable them to address fear, discomfort, and anxieties about HIV/AIDS.

\section{CONCLUSION}

The HCS have the chance of regular interaction with PLHIV. The knowledge is the key factor to eliminate fear and stigma from the students and HIV-infected people. The present study findings revealed that majority of the HCS $274(46 \%)$ had inadequate knowledge, so they need to have adequate knowledge on HIV and AIDS. Hence, there is a need of intense teaching program with various teaching methods.

\section{REFERENCES}

1. Pablo LC, Cândido DS, Loureiro CV, Carlos JO, Araújo AM, Batista MJ, et al. Evaluation of clinical parameters in people living with HIV undergoing pharmaco therapeutic monitoring: Viral load, CD4+ T lymphocytes and adherence to antiretroviral. Afr J Pharm Pharmacol 2016;10(12):236-43.

2. Caroline O, Temitope OA. Undergraduate students' perception of HIV/AIDS. J Clin Res HIV Aids Pre 2016:2(3);2324-7339.

3. UNAIDS. Available from: https://www.unaids.org/en/resources/ fact-sheet. [Last accessed on 2005].

4. WHO/HIV/AIDS. 2016. Available from: https://www.who.int/ mediacentre/factsheets/fs360/en.

5. CDC. 2015. Available from: https://www.cdc.gov/nchs/data/nvsr/ nvsr64/nvsr64 12.pdf.

6. Grover N, Prakash A, Singh S, Singh N, Singh P, Nazeer J. Attitude and knowledge of dental students of national capital region regarding HIV and AIDS. J Oral Maxillofac Pathol 2014;18(1):9-13.

7. Hamid Albujeer AN, Shamshiri AR, Taher A. HIV/AIDS awareness among Iraqi medical and dental students. J Int Soc Prev Community Dent 2015;5(5):372-6.

8. Naveen KG, Rahul B, Rambha P, Sharma HK, Monika A, Luthra SC. Knowledge and awareness of nursing students about HIV/AIDS. Health Popul Perspect Issues 2010;33(1):55-60.

9. Christina O, Konstantinos N. Knowledge and awareness of nursing students about HIV/AIDS. Health Sci J 2012;6(1):129-50. 